\title{
Evaluation of psychometric properties of Walking Impairment Questionnaire in overweight patients with osteoarthritis of knee
}

\author{
Eileen Collins, PhD, RN; ${ }^{1-2 *}$ Susan O’Connell, MHA, RN; ${ }^{1}$ Christine Jelinek, MS; ${ }^{1}$ Scott Miskevics, BS; ${ }^{1}$ \\ Elly Budiman-Mak, MD ${ }^{1,3}$ \\ ${ }^{1}$ Center for Management of Complex Chronic Care, Edward Hines Jr Department of Veterans Affairs Hospital, Hines, IL; \\ ${ }^{2}$ College of Nursing, University of Illinois at Chicago, Chicago, $I L ;{ }^{3}$ Stritch School of Medicine, Loyola University of \\ Maywood, Chicago, IL
}

\begin{abstract}
This study tested the psychometric properties of the Walking Impairment Questionnaire (WIQ) in overweight patients with osteoarthritis (OA) of the knee. Internal consistency, test-retest reliability, and concurrent validity of the WIQ were measured. Used in a randomized clinical trial, the WIQ was one of the instruments completed by overweight adults with OA of the knee. A total of 105 patients completed the WIQ. Internal consistency of the WIQ was supported in this population with a Cronbach alpha total score of 0.97. Testretest reliability scores were not different when subjects completed the WIQ 14 days apart $(p>0.05)$. The relationships were moderate between the WIQ subscales and other established measures, such as the 6-minute walk distance, stair climb and descend, and the Western Ontario and McMaster Universities (OA Index) questionnaire. After evaluating the psychometric properties of the WIQ, we found that it is a valid and reliable instrument to use in overweight patients with symptomatic OA of the knee.
\end{abstract}

Clinical Trial Registration: ClinicalTrials.gov; Home-Based Exercise and Nutrition Program for Pain Control in Overweight Elderly Osteoarthritics, NCT00126737;

$<$ http://www.clinicaltrials.gov $>$.

Key words: body mass index, difficulty walking, exercise, measurement, osteoarthritis, osteoarthritis knee, overweight, questionnaires, rehabilitation, reliability, validity, walking.

\section{INTRODUCTION}

Osteoarthritis (OA) is the most common chronic disease in the United States. OA is second only to heart disease as a cause of activity limitation in adults aged 65 and older; 75 million persons in the United States experience joint and muscle pain, and the knee joints are most commonly affected [1]. Approximately 40 percent of individuals aged 60 and over have OA of the knee [2], resulting in weakened muscles of the involved joints, increased weight, decreased aerobic capacity, and reduced tolerance for activities of daily living, including walking.

Walking ability is impaired in patients with OA of the knee because of pain and stiffness in the joint [3-5], instability in the joint, and weak quadriceps muscles [6].

Abbreviations: ARA $=$ American Rheumatism Association, $\mathrm{BMI}=$ body mass index, $\mathrm{CI}=$ confidence interval, $\mathrm{ICC}=$ intraclass correlation coefficient, $\mathrm{OA}=$ osteoarthritis, $\mathrm{PAD}=$ peripheral artery disease, $\mathrm{SD}=$ standard deviation, $\mathrm{VA}=$ Department of Veterans Affairs, WIQ = Walking Impairment Questionnaire, WOMAC $=$ Western Ontario and McMaster Universities (OA Index).

*Address all correspondence to Eileen Collins, PhD, RN; Research \& Development (151), Edward Hines Jr VA Hospital, Hines, IL 60141; 708-202-3525; fax: 708-202-3906.

Email: eileen.collins@va.gov

DOI: 10.1682/JRRD.2007.04.0053 
The 6-minute walk distance recorded in patients with OA of the knee (400-440 m) [3-5] is similar to patients with chronic heart failure (445 m) [7] and chronic obstructive pulmonary disease (371 $\mathrm{m}$ ) [8] and less than healthy elderly patients (524 m) [9]. To date, researchers have focused on measuring difficulty with physical function, including walking, in patients with OA of the knee using the Western Ontario and McMaster Universities (WOMAC) OA Index questionnaire [4] and the Functional Performance Inventory [10]. Since more factors than simply walking influence physical function, the relationship between selfreported physical function and performance measures, such as the 6-minute walk, is low [4]. This population has a need for a valid and reliable instrument to specifically measure walking ability.

In patients with peripheral artery disease (PAD), the Walking Impairment Questionnaire (WIQ) was designed to measure their perception of their walking distance, walking speed, and stair-climbing ability [11-12]. It has subsequently been used extensively in patients with PAD [11-18] and stroke [19]. In patients with PAD, the WIQ distance and speed subscales have been correlated with walking time on the treadmill [11,14-15,20-21]. Additionally, the WIQ distance and speed subscales have been responsive to various exercise rehabilitation training programs [11,14-15,20-21].

Since walking ability is impaired in patients with OA of the knee and no established self-report instrument exists to measure walking endurance expressed in distance and speed in this population, we sought to measure the psychometric properties of the WIQ in patients with OA of the knee. We hypothesized that the WIQ would be a reliable and valid instrument for measuring walking endurance, walking speed, and stair-climbing ability in patients with OA of the knee.

\section{METHODS}

\section{Procedures}

A prospective, randomized clinical trial was completed in overweight and obese adults with painful OA of the knee. The study was conducted from 2002 to 2005 at the Edward Hines Jr Department of Veterans Affairs (VA) Hospital in Hines, Illinois. The objectives of this trial were to reduce pain in the knee through a weight loss and/or exercise program. While we used standard measuring tools for quantitative and qualitative measures of study outcomes, we also tested the participants' perceptions of their walking ability using the WIQ.

The WIQ was self-administered according to study protocol at baseline, 16, 24, and 32 weeks. The study nurse then reviewed the WIQ with the patient for any missing data. To obtain test-retest reliability information, we administered the WIQ to a subset of patients $(n=16)$ 2 weeks apart. The 6 -minute walk distance, 3-minute stair climb and descend, WOMAC scores, and demographic variables were used for describing concurrent validity.

\section{Subject Selection}

After the Human Studies Subcommittee approved the study, patients with documented OA of the knee were recruited from the General Medicine and Arthritis Clinics at Edward Hines Jr VA Hospital and the surrounding community. Subjects were identified using International Classification of Diseases-9th Revision codes 715.06 or 715.26 as a primary or secondary diagnosis. Identified subjects were sent a letter of invitation. To be contacted by the staff, the subject needed to respond positively to the letter of invitation by returning a stamped selfaddressed information sheet. Subjects were then invited for an initial laboratory visit, and written informed consent was obtained.

\section{Inclusion Criteria}

Subjects aged 50 or older with documented OA of the knee were invited to participate. OA of the knee was documented as radiographic findings of tibiofemoral joint changes of grades II to III with the use of the Kellgren and Lawrence criteria [22]. Additionally, patients needed to be symptomatically defined as self-reported mild to severe pain for most days of the week for at least 6 months before study entry, be functional Classes I-III of the American Rheumatism Association (ARA), and have a body mass index (BMI) $\geq 27$ and $\leq 40$. Patients were allowed to adjust their analgesics as necessary throughout the study. Finally, they needed to be able to attend scheduled exercise and nutrition counseling sessions.

\section{Exclusion Criteria}

Patients were excluded if knee arthritis did not meet ARA OA criteria; comorbid conditions precluded participation in the exercise program; arthroscopic surgery of the knee was completed within the previous 3 months; severe back, hip, or ankle pain stopped the patient from 
walking; claudication pain stopped the patient from walking; or both knee joints had been replaced. Claudication pain was defined as self-reported calf, thigh, or buttock pain that was brought on by walking and subsided with rest.

\section{Measures}

\section{Walking Impairment Questionnaire}

The WIQ is a subjectively measured, self-administered instrument consisting of a 14-item survey with three subscales: walking distance (7 items), walking speed (4 items), and stair-climbing ability (3 items). The WIQ has two additional subscales asking questions specifically related to PAD (pain, aching, or cramps in the calves or buttocks) and differential diagnosis to rule out other causes of walking impairment (e.g., pain, stiffness or aching in the joints, chest pain, shortness of breath, or heart palpitations). At study entry, we asked participants to complete the WIQ in the Exercise Physiology Laboratory.

The WIQ measures an individual's mobility and degree of difficulty in performing the tasks. All responses are scored on a 0 to 4 Likert scale ( $4=$ none, $3=$ slight, $2=$ some, $1=$ much difficulty, and $0=$ unable to do). Specifically, the WIQ assesses subjects' self-reported difficulty in walking a defined distance (1/2 or less, 1,2 , or 3 city blocks); difficulty in how fast they are able to walk one block (walking one block slowly, at an average speed, or quickly, or running or jogging one block); and difficulty climbing one, two, and three flights of stairs.

The WIQ is scored by multiplication of the degree of difficulty by a predefined number to represent distance (feet), speed (miles/hour), or stairs climbed (steps). The derived number is divided by the total possible score. A whole number percentage is then obtained by multiplication of this value by 100 .

\section{6-Minute Walk}

The 6-minute walk is a test where the subject walks for 6 minutes on level ground, and the distance covered in 6 minutes is measured [23]. The walk test is carried out in a $100 \mathrm{ft}-$ level indoor straight corridor of the hospital. Subjects are instructed to cover as much ground as possible in 6 minutes. Patients are asked to walk continuously, if possible, but they are permitted to slow down or stop if they feel the need to do so. The goal of the test is to have subjects adopt a self-selected walking speed such that at the end of 6 minutes, they will feel that they could not have walked any farther. Standard encouragement is used and subjects are told when they have walked 1,3 , and 5 minutes.

\section{Climbing and Descending Stairs}

For assessment of stair-climbing and -descending ability, subjects climb and descend a standard set of stairs for 3 minutes. At the signal to begin, subjects climb four steps up, encounter a small landing at the top, and descend four steps down. When subjects reach the bottom of the four stairs, they turn $180^{\circ}$ and climb and descend again [24]. For 3 minutes, subjects move continuously completing as many stairs as possible in the allotted time. An electrocardiogram is monitored continuously throughout the stair climbing and descending. If subjects need to stop before the 3 minutes are completed, they are instructed to simply stop where they are.

\section{Western Ontario and McMaster Universities Osteoarthritis Index}

The WOMAC questionnaire is designed to measure functional loss and pain in persons with hip and knee arthritis [25-26]. The WOMAC is a disease-specific measure of factors affecting quality of life in persons with OA of the hip and knee. It is made up of 17 functional activity items, 5 pain-related items, and 2 stiffness items rated on a Likert scale. The WOMAC has demonstrated strong psychometric properties in a variety of clinical trials involving patients with $\mathrm{OA}$ of the knee $[16,25,27-29]$.

\section{Body Composition}

The BOD POD (Life Measurement, Inc; Concord, California) is used to measure body weight and body fat percentage. The BOD POD uses air displacement to determine body density, and standard equations are then used for computing body fat percentage. Results from the BOD POD and underwater weighing were almost identical $( \pm 0.3 \%)$ [30]. Similarly, the correlation between dualenergy X-ray absorptiometry scan and BOD POD measurements was high $(r=0.91, p<0.01)$ [31]. The mean \pm standard deviation (SD) test-retest reliability was also very high $(1.7 \% \pm 1.1 \%$ difference for BOD POD vs $2.3 \% \pm$ $1.9 \%$ for underwater weighing) [30].

\section{Statistical Analysis}

We used descriptive statistics to depict the sample characteristics (mean \pm SD) and intraclass correlation coefficients (ICCs) to complete test-retest reliability. 
Pearson $r$ correlation coefficients were used for assessing the relationship between the WIQ distance, speed, and stair-climbing scores at baseline with selected measures, i.e., items from WOMAC and demographic characteristics (concurrent validity). Although data were collected at baseline, 16, 24, and 32 weeks, only baseline data are considered for analysis. We used Cronbach $\alpha$ statistics to determine internal consistency of the WIQ. A two-tailed $\alpha$ of 0.05 was considered significant. We used the SPSS, version 13.0, statistical analysis program (SPSS, Inc; Chicago, Illinois) to complete the analysis.

\section{RESULTS}

One hundred twelve participants were randomized in the study. Complete WIQ baseline data were available on 105 subjects. Seven participants either had missing data on the questionnaire or did not complete the questionnaire at baseline and were not used in the analysis.

\section{Subject Characteristics}

The sample of subjects consisted of adults ranging from 50 to 88 years old who reported having OA of the knee for an average of 10 years. Table 1 provides information on additional sample characteristics. Descriptive information on the WIQ, the WOMAC, the 6-minute walk distance, and the total number of stairs climbed and descended is presented in Table 2.

\section{Reliability}

The Cronbach $\alpha=0.97$ for the total score on the WIQ. The Cronbach $\alpha$ for the respective subscales distance, speed, and stair-climbing $=0.96,0.87$, and 0.94, respectively.

\section{Reproducibility}

Test-retest reliability was completed with a subset of 16 subjects. Subjects completed the WIQ 14 days apart. Scores (mean $\pm \mathrm{SD}$ ) on the respective subscales differed by $2.75 \pm 14.42$ points on the distance subscale $(p=0.46)$, $2.51 \pm 13.50$ points on the speed subscale $(p=0.47)$, and $6.25 \pm 13.35$ points on the stair-climbing subscale $(p=$ $0.08)$. ICCs were high for all subscales from time 1 to time 2-distance: ICC $=0.87, p<0.001,95 \%$ confidence interval (CI) $=0.67-0.95$; speed: ICC $=0.86, p<0.001$, 95\% CI $=0.65-0.95$; and stair-climbing: ICC $=0.87, p<$ $0.001,95 \%$ CI $=0.65-0.95$.
Table 1.

Demographic information of subjects with osteoarthritis of knee $(N=105)$.

\begin{tabular}{lc}
\hline \multicolumn{1}{c}{ Characteristic } & Mean \pm SD or \% \\
\hline Sex (male) & 88.57 \\
Race & 89.52 \\
Caucasian & 6.66 \\
African American & 3.81 \\
All Other & $64.47 \pm 8.40$ \\
Age (yr) & $173.55 \pm 8.30$ \\
Height (cm) & $103.48 \pm 19.25$ \\
Weight (kg) & $34.49 \pm 5.94$ \\
Body Mass Index (kg/m ${ }^{2}$ ) & $39.74 \pm 8.19$ \\
Body Fat (\%) & 81.90 \\
ARA Classification & 15.24 \\
Class I & 2.86 \\
Class II & \\
Class III & \\
Kellgren-Lawrence Classification & 56.20 \\
Grade II & 44.80 \\
Grade III & \\
\hline ARA = American Rheumatism Association, SD = standard deviation. \\
\hline \hline
\end{tabular}

Table 2.

Descriptive information on selected variables of subjects with osteoarthritis of knee $(N=105)$.

\begin{tabular}{lcr}
\hline \multicolumn{1}{c}{ Measure } & Mean \pm SD & Range \\
\hline WIQ Subscales & $46.85 \pm 28.66$ & $0.14-100$ \\
Distance & $39.46 \pm 22.72$ & $0-100$ \\
Speed & $46.69 \pm 26.17$ & $0-100$ \\
$\quad$ Stair-Climbing & \\
WOMAC Subscales & $12.29 \pm 3.45$ & $5-24$ \\
$\quad$ Pain & $5.64 \pm 1.60$ & $2-10$ \\
Stiffness & $41.71 \pm 12.35$ & $17-80$ \\
Function & $59.62 \pm 16.09$ & $28-114$ \\
$\quad$ Total & $443.78 \pm 102.67$ & $175-659$ \\
6-Minute Walk Distance (m) & $176.03 \pm 52.83$ & $64-293$ \\
Total Stairs Ascended/Descended (No.) & (17.03 \\
SD = standard deviation, WIQ = Walking Impairment Questionnaire, WOMAC $=$ \\
Western Ontario and McMaster Universities (Osteoarthritis Index). \\
\hline \hline
\end{tabular}

\section{Validity}

Concurrent validity was supported by a moderate relationship between the WIQ distance subscale and the 6 -minute walk distance $(r=0.52, p<0.001)$. A similar relationship was identified between the WIQ speed subscale and the 6-minute walk distance $(r=0.51, p<$ 0.001). A relationship was also found between the WIQ stair-climbing subscale and the actual number of stairs ascended and descended in the 3-minute test $(r=0.44$, 
scales would not be as strong. Similarly, subjects who reported having $\mathrm{OA}$ of the knee longer reported lower scores on the WIQ. This finding suggests that more advanced degenerative changes may have occurred in the knee joint over time. Future research would be needed to support whether or not the WIQ is responsive to the severity of the OA of the knee.

Since the WIQ has been used primarily in patients with PAD, we compared scores in this sample with previously reported data on the PAD population. Average scores obtained on the WIQ subscales in patients with OA are slightly higher than those reported by patients with PAD and lower than those without PAD [1314,21,32-39]. In patients with PAD, scores on the walking distance subscale ranged from 25 to 56 [13-14,32$35,37,39]$, with most scores clustering at 40 or lower. In patients whose lifestyle was limited by decreased circulation to their legs or who were awaiting surgery, scores were lower, ranging from 3.1 to 12.6 [36,38]. Conversely, subjects without PAD who completed the WIQ distance subscale reported scores ranging from 73 to 79 [32,35]. The patients with OA scored $46.9 \pm 28.7$ on the WIQ walking distance subscale (scores given as mean \pm SD unless otherwise noted). The scores are in the upper range of PAD patients and well below those reported by patients without disease. Likewise, patients with decreased circulation to the legs scored between 30 and 39 [13-14,32-35,37,39] on the walking speed subscale, with severely limited PAD patients scoring between 4.6 and 22.0 [36,38]. Subjects without disease reported scores ranging from 60 to 64 [32,35]. Patients in the present study with OA of the knee reported a walking speed subscale score of $39.5 \pm 22.7$. This score, as is the walking distance score, is higher than those reported by people with PAD. Most subjects in this study were in the Kellgren-Lawrence grades II to III [22], indicating moderate $\mathrm{OA}$ degenerative changes, and were classified as ARA functional Classes I and II. On the stair-climbing subscale, patients with PAD reported scores ranging from 46 to $64[13-14,32-35,37,39]$ and patients with limited lifestyles were between 10.7 and 32.0 [36,38]. Subjects without disease reported scores of 63 to 70 [32,35]. Subjects with OA of the knee reported scores of $46.7 \pm 26.2$. Because of the difficult maneuvering actions and weightbearing burden on the knees, climbing stairs is a very difficult task for people with OA of the knee. Thus patient scores are not surprisingly lower than those reported by patients with PAD.
Using the WIQ in the population with OA of the knee has many advantages. First, the instrument is selfadministered and contains familiar tasks in which the individual engages. Next, it contains only 14 items and the subjects completed it in less than 10 minutes. As such, researchers can conveniently use the WIQ in large studies to measure walking ability in dimensions not previously measured by the existing instruments [15-17]. Future research documenting outcomes of clinical trials using the WIQ is warranted. Finally, if validated in other populations of subjects with lower-limb disabilities and a wider range of knee OA severity, the WIQ may be used as a benchmark measure for walking ability across a broad spectrum of patients.

Our study was limited by the small number of women enrolled in the study; hence, generalizability across sex could be limited. We cannot state with certainty that the WIQ would perform in the same manner if more women participated in the study.

\section{CONCLUSIONS}

These data suggest that the WIQ is a valid and reliable measure of walking impairment in patients with OA of the knee. In large clinical trials of patients with OA of the knee where objective measures of walking ability are not feasible, the WIQ's ease of use offers a clear advantage for researchers and investigators in measuring walking ability. Changes in walking distance and speed are important outcomes for pharmacotherapy trials; the WIQ may better predict clinically important changes in walking ability than the currently available measures.

\section{ACKNOWLEDGMENTS}

This material was based on work supported by grant E2-2362RA from the VA Rehabilitation Research and Development Service.

The authors have declared that no competing interests exist.

\section{REFERENCES}

1. Desai MM, Zhang P, Hennessy CH. Surveillance for morbidity and mortality among older adults-United States, 1995-1996. Morbidity and Mortality Weekly Report: CDC 
Surveillance Summaries; 1999 Dec 17, Vol. 48, No. SS-8. Atlanta (GA): Centers for Disease Control and Prevention; 1999. p. 7-26.

2. Kovar PA, Allegrante JP, Mackenzie CR, Peterson MG, Gutin B, Charlson ME. Supervised fitness walking in patients with osteoarthritis of the knee. A randomized, controlled trial. Ann Intern Med. 1992;116(7):529-34. [PMID: 1543305]

3. Stratford PW, Kennedy DM, Woodhouse LJ. Performance measures provide assessments of pain and function in people with advanced osteoarthritis of the hip or knee. Phys Ther. 2006;86(11):1489-96. [PMID: 17079748]

4. Stratford PW, Kennedy DM. Performance measures were necessary to obtain a complete picture of osteoarthritic patients. J Clin Epidemiol. 2006;59(2):160-67. [PMID: 16426951]

5. Maly MR, Costigan PA, Olney SJ. Determinants of self-report outcome measures in people with knee osteoarthritis. Arch Phys Med Rehabil. 2006;87(1):96-104. [PMID: 16401446]

6. Schmitt LC, Rudolph KS. Influences on knee movement strategies during walking in persons with medial knee osteoarthritis. Arthritis Rheum. 2007;57(6):1018-26. [PMID: 17665469]

7. Kervio G, Ville NS, Leclercq C, Daubert J, Carré F. Intensity and daily reliability of the six-minute walk test in moderate chronic heart failure patients. Arch Phys Med Rehabil. 2004; 85(9):1513-18. [PMID: 15375827]

8. Sciurba F, Criner GJ, Lee SM, Mohsenifar Z, Shade D, Slivka W, Wise RA; National Emphysema Treatment Trial Research Group. Six-minute walk distance in chronic obstructive pulmonary disease: reproducibility and effect of walking course layout and length. Am J Respir Crit Care Med. 2003;167(11):1522-27. [PMID: 12615634$]$

9. Kervio G, Carré F, Ville NS. Reliability and intensity of the six-minute walk test in healthy elderly subjects. Med Sci Sports Exerc. 2003;35(1):169-74. [PMID: 12544651]

10. Ettinger WH Jr, Burns R, Messier SP, Applegate W, Rejeski WJ, Morgan T, Shumaker S, Berry MJ, O’Toole $\mathrm{M}$, Monu J, Craven T. A randomized trial comparing aerobic exercise and resistance exercise with a health education program in older adults with knee osteoarthritis. The Fitness Arthritis and Seniors Trial (FAST). JAMA. 1997; 277(1):25-31. [PMID: 8980206]

11. Regensteiner JG, Steiner JF, Panzer RJ, Hiatt WR. Evaluation of walking impairment by questionnaire in patients with peripheral arterial disease. J Vasc Med Biol. 1990;2: 142-52.

12. Hiatt WR, Hoag S, Hamman RF. Effect of diagnostic criteria on the prevalence of peripheral arterial disease. Circulation. The San Luis Valley Diabetes Study. 1995;91(5): 1472-79. [PMID: 7867189]

13. McDermott MM, Liu K, Guralnik JM, Martin GJ, Crique $\mathrm{MH}$, Greenland P. Measurement of walking endurance and walking velocity with questionnaire: Validation of the walking impairment questionnaire in men and women with peripheral arterial disease. J Vasc Surg. 1998;28(6):1072-81. [PMID: 9845659]

14. Collins EG, Langbein WE, Orebaugh C, Bammert C, Hanson K, Reda D, Edwards LC, Littooy FN. PoleStriding exercise and vitamin $\mathrm{E}$ for management of peripheral vascular disease. Med Sci Sports Exerc. 2003;35(3):384-93. [PMID: 12618567]

15. Regensteiner JG, Steiner JF, Hiatt WR. Exercise training improves functional status in patients with peripheral arterial disease. J Vasc Surg. 1996;23(1):104-15. [PMID: 8558725]

16. McDermott MM, Ohlmiller SM, Liu K, Guralnik JM, Martin GJ, Pearce WH, Greenland P. Gait alterations associated with walking impairment in people with peripheral arterial disease with and without intermittent claudication. J Am Geriatr Soc. 2001;49(6):747-54. [PMID: 11454113]

17. Hiatt WR. Medical treatment of peripheral arterial disease and claudication. New Engl J Med. 2001;344(21):1608-21. [PMID: 11372014]

18. Feinglass J, McCarthy WJ, Slavensky R, Manheim LM, Martin GJ. Effect of lower extremity blood pressure on physical functioning in patients who have intermittent claudication. The Chicago Claudication Outcomes Research Group. J Vasc Surg. 1996;24(4):503-11. [PMID: 8911399]

19. Macko RF, Ivey FM, Forrester LW, Hanley D, Sorkin JD, Katzel LI, Silver KH, Goldberg AP. Treadmill exercise rehabilitation improves ambulatory function and cardiovascular fitness in patients with chronic stroke: a randomized, controlled trial. Stroke. 2005;36(10):2206-11. [PMID: 16151035]

20. Regensteiner JG, Hiatt WR. Exercise rehabilitation for patients with peripheral arterial disease. Exerc Sport Sci Rev. 1995;23:1-24. [PMID: 7556347]

21. Langbein WE, Collins EG, Orebaugh C, Maloney C, Williams KJ, Littooy FN, Edwards LC. Increasing exercise tolerance of persons limited by claudication pain using polestriding. J Vasc Surg. 2002;35(5):887-93. [PMID: 12021703]

22. Kellgren JH, Lawrence JS. Radiological assessment of osteo-arthritis. Ann Rheum Dis. 1957;16(4):494-502. [PMID: 13498604]

23. Hamilton DM, Haennel RG. Validity and reliability of a 6minute walk test in a cardiac rehabilitation population. J Cardiopulm Rehabil. 2000;20(3):156-64. [PMID: 10860197]

24. Hagarty EM, Skorodin MS, Langbein WE, Hultman CI, Jessen JA, Maki KC. Comparison of three oxygen delivery systems during exercise in hypoxemic patients with chronic obstructive pulmonary disease. Am J Respir Crit Care Med. 1997;155(3):893-98. [PMID: 9117023]

25. Davies GM, Watson DJ, Bellamy N. Comparison of the responsiveness and relative effect size of the western Ontario and McMaster Universities Osteoarthritis Index and the 
short-form Medical Outcomes Study Survey in a randomized, clinical trial of osteoarthritis patients. Arthritis Care Res. 1999;12(3):172-79. [PMID: 10513507]

26. Wolfe F, Kong SX. Rasch analysis of the Western Ontario MacMaster questionnaire (WOMAC) in 2205 patients with osteoarthritis, rheumatoid arthritis, and fibromyalgia. Ann Rheum Dis. 1999;58(9):563-68. [PMID: 10460190]

27. O’Reilly SC, Muir KR, Doherty M. Effectiveness of home exercise on pain and disability from osteoarthritis of the knee: a randomised controlled trial. Am Rheum Dis. 1999; 58(1):15-19. [PMID: 10343535]

28. Deyle GD, Henderson NE, Matekel RL, Ryder MG, Garber MB, Allison SC. Effectiveness of manual physical therapy and exercise in osteoarthritis of the knee. A randomized, controlled trial. Ann Intern Med. 2000;132(3):173-81. [PMID: 10651597]

29. Tinetti ME, Baker DI, McAvay G, Claus EB, Garrett P, Gottschalk M, Koch ML, Trainor K, Horwitz RI. A multifactorial intervention to reduce the risk of falling among elderly people living in the community. $\mathrm{N}$ Engl $\mathrm{J}$ Med. 1994;331(13):821-27. [PMID: 8078528$]$

30. McCrory MA, Gomez TD, Bernauer EM, Molé PA. Evaluation of a new air displacement plethysmograph for measuring human body composition. Med Sci Sports Exerc. 1995;27(12):1686-91. [PMID: 8614326]

31. Miyatake N, Nonaka K, Fujii M. A new air displacement plethysmograph for the determination of Japanese body composition. Diabetes Obes Metab. 1999;1(6):347-51. [PMID: 11225651]

32. McDermott MM, Mehta S, Liu K, Guralnik JM, Martin GJ, Criqui MH, Greenland P. Leg symptoms, the ankle-brachial index, and walking ability in patients with peripheral arterial disease. J Gen Intern Med. 1999;14(3):173-81. [PMID: 10203623]

33. Izquierdo-Porrera AM, Gardner AW, Powell CC, Katzel LI. Effects of exercise rehabilitation on cardiovascular risk fac- tors in older patients with peripheral arterial occlusive disease. J Vasc Surg. 2000;31(4):670-77. [PMID: 10753274$]$

34. Regensteiner JG, Ware JE Jr, McCarthy WJ, Zhang P, Forbes WP, Heckmen J, Hiatt WR. Effect of cilostazol on treadmill walking, community-based walking ability, and healthrelated quality of life in patients with intermittent claudication due to peripheral arterial disease: meta-analysis of six randomized controlled trials. J Am Geriatr Soc. 2002;50(12): 1939-46. [PMID: 12473004]

35. Hirsch AT, Crique MH, Treat-Jacobson D, Regensteiner JG, Creager MA, Olin JW, Krook SH, Hunninghake DB, Comerota AJ, Walsh ME, McDermott MM, Hiatt WR. Peripheral arterial disease detection, awareness, and treatment in primary care. JAMA. 2001;286(11):1317-24. [PMID: 11560536]

36. Long J, Modrall JG, Parker BJ, Swann A, Welborn MB 3rd, Anthony T. Correlation between ankle-brachial index, symptoms, and health-related quality of life in patients with peripheral vascular disease. J Vasc Surg. 2004;39(4): 723-27. [PMID: 15071432]

37. Wullink M, Stoffers HE, Kuipers H. A primary care walking exercise program for patients with intermittent claudication. Med Sci Sports Exerc. 2001;33(10):1629-34. [PMID: 11581544]

38. Murphy TP, Soares GM, Kim HM, Ahn SH, Haas RA. Quality of life and exercise performance after aortoiliac stent placement for claudication. J Vasc Interv Radiol. 2005;16(7): 947-54. [PMID: 16002502]

39. Coyne KS, Margolis MK, Gilchrist KA, Grandy SP, Hiatt WR, Ratchford A, Revicki DA, Weintraub WS, Regensteiner JG. Evaluating effects of method of administration on Walking Impairment Questionnaire. J Vasc Surg. 2003; 38(2):296-304. [PMID: 12891111]

Submitted for publication April 3, 2007. Accepted in revised form November 5, 2007. 